\title{
Increased Angiotensin-converting Enzyme in Peripheral Blood Monocytes from Patients with Sarcoidosis
}

Tetsuro Okabe, Kazuo Yamagata, Michio Fujisawa, Junichi Watanabe, and Fumimaro Takaku

Third Department of Internal Medicine, Faculty of Medicine, University of Tokyo, Tokyo 113, Japan

Joseph J. Lanzillo and Barry L. Fanburg

Department of Medicine, New England Medical Center Hospital, Tufts University School of Medicine, Boston, Massachusetts 02111

\begin{abstract}
Angiotensin-converting enzyme (ACE) activity was measured in isolated peripheral blood monocytes and culture medium from 28 patients with sarcoidosis and compared with values obtained from monocytes of 25 normal control subjects. ACE activity was determined by radioimmunoassay of angiotensin II produced from angiotensin I. While there was no measurable ACE activity in monocytes or culture medium from normal controls under the conditions of our study, monocytes from patients with sarcoidosis all showed activity both in cells and culture medium. The mean ACE activity of monocytes from patients with sarcoidosis was $2.0 \mathrm{pg}$ angiotensin II formed/ min per $10^{5}$ cells, and that released into medium over a 24-h interval was $30.4 \mathrm{pg}$ angiotensin $\mathrm{II} / \mathrm{min}$ per $10^{5}$ cells. The monocyte ACE from patients with sarcoidosis was activated by chloride ions and inhibited by EDTA, captopril, and rabbit antiserum to purified human plasma ACE, indicating that enzymatic activity was effected specifically by ACE. Thus, our studies show a significant elevation and release of ACE by peripheral blood monocytes of patients with sarcoidosis under conditions where monocytes of normal control subjects do not demonstrate ACE activity.
\end{abstract}

\section{Introduction}

Sarcoidosis, a disease of unknown origin and worldwide distribution, is characterized by a generalized formation of nonnecrotizing granulomas, which are composed characteristically of epithelioid cells, multinucleated giant cells, and small cells (1). A significant elevation of serum angiotensin-converting enzyme (ACE) $)^{1}$ occurs in somewhere between 34 and $88 \%$ of patients with sarcoidosis (2-5). The localization of ACE in epithelioid and giant cells of sarcoid granulomas, the marked increase in ACE activity in sarcoid granulomatous lymph nodes (6-8), and the biosynthetically active fine structural appearance of sarcoid epithelioid cells (9) strongly suggest that sarcoid granulomas may be responsible for the increased serum ACE activity. This concept is further supported by our recent observation that cultured epithelioid cells from sarcoid lymph nodes spontaneously release large quantities of ACE into the

Address reprint requests to Dr. Okabe.

Received for publication 22 October 1984.

1. Abbreviations used in this paper: ACE, angiotensin-converting enzyme; BPP, bradykinin-potentiating peptide B.

J. Clin. Invest.

(c) The American Society for Clinical Investigation, Inc.

0021-9738/85/03/911/04 $\$ 1.00$

Volume 75, March 1985, 911-914 culture medium (10). Alveolar macrophages, which are believed to be precursors of epithelioid and giant cells, contain significant amounts of ACE (11). Studies done with patients receiving allogeneic bone marrow transplants from siblings of the opposite sex support the concept that alveolar macrophages are derived from bone marrow and may arrive in the lung through transit as monocytes in the blood (12). If monocytes of the circulating blood are precursors of the sarcoid epithelioid cells, it may be anticipated that elevated levels of ACE activity in granulomas of patients with sarcoidosis may be associated with elevations of enzymatic activity in circulating monocytes. The present study was undertaken to evaluate this hypothesis.

\section{Methods}

Subjects for studies. The studies were carried out on 28 patients with sarcoidosis whose diagnosis was made on the basis of clinical findings, chest roentgenographic examination, and the presence of nonnecrotizing granulomas in biopsied specimens from scalene lymph nodes which were devoid of acid-fast bacilli, fungi, or other agents on microscopic examination and culture. The ages of the patients with sarcoidosis ranged from 25 to $75 \mathrm{yr}$; there were 7 males and 21 females in the group. Roentgenographic classifications ranged from class 1 to class 3 . Serum ACE levels were $50.2 \pm 24.5 \mathrm{U} / \mathrm{ml}$. The control group consisted of 25 healthy donors who ranged in age from 22 to $67 \mathrm{yr}$. There were 9 males and 16 females in this group. Serum ACE levels of controls were $22.6 \pm 13.4 \mathrm{U} / \mathrm{ml}$.

Isolation of mononuclear cells. $10 \mathrm{ml}$ of fresh heparinized blood were obtained from each individual, and mononuclear cells were isolated by Ficoll density gradient centrifugation (LMS solution; Bionetics Laboratory Products, Kensington, MD) according to the method of Böyum (13). After two washes of cells in Hams F-10 nutrient medium (Flow Laboratories Inc., Rockville, MD) at room temperature, the cells were suspended in this medium. Greater than $97 \%$ of the cells were viable as determined by trypan blue exclusion.

Culture of monocytes. The mononuclear cells isolated by density gradient centrifugation were incubated in plastic petri dishes $(60 \times 15$ $\mathrm{mm}$; Falcon Labware, Div. of Becton, Dickinson \& Co., Oxnard, CA) at a concentration of $2 \times 10^{6} \mathrm{cells} / \mathrm{ml}$ per dish for $2 \mathrm{~h}$ at $37^{\circ} \mathrm{C}$ in a $5 \% \mathrm{CO}_{2}$ atmosphere. After this incubation period, the nonadherent cells were removed and the dishes were rinsed with warm F-10 medium. The adherent cells were then incubated in F-10 medium.

All cell counts were done in duplicate on cell cultures grown in parallel with those used for ACE measurements. For counting, cells were harvested in F-10 medium containing $0.8 \%$ xylocaine (Fujisawa Pharmaceutical Co., Ltd., Osaka, Japan) (14). The monocyte monolayers were washed twice with $4 \mathrm{ml}$ of $\mathrm{F}-10$ medium, $2 \mathrm{ml}$ of $0.8 \%$ xylocaine was added to each dish, and the cells were incubated at $37^{\circ} \mathrm{C}$ for 15 min. $2 \mathrm{ml}$ of F-10 medium that contained $10 \%$ fetal bovine serum (Flow Laboratories Inc.) was then added, and the detached cells were collected and counted with the aid of a hemocytometer. Microscopic examination showed no residual cells in the dishes after treatment. The cell numbers from two monolayers were used to calculate the mean cell number. The monocyte content of this cell preparation quantitated by nonspecific esterase activity was $89 \pm 1.6 \%$ (15). 
ACE activity associated with cells. For measurement of ACE activity associated with cells, cells in monolayer cultures were removed with a rubber policeman, washed with $\mathrm{F}-10$ medium, sonicated at $0^{\circ} \mathrm{C}$ for four 10-s intervals, and partially solubilized in $0.5 \mathrm{ml}$ of $0.01 \mathrm{M}$ Tris $\mathrm{HCl}, \mathrm{pH} \mathrm{7.4,} \mathrm{in} \mathrm{the} \mathrm{presence} \mathrm{of} 0.5 \%$ Nonidet P-40 (NP-40, Nakarai Chemicals Ltd., Kyoto, Japan), a nonionic detergent used in the initial purification procedure for converting enzyme (16). 100- $\mu 1$ samples were assayed for ACE activity.

Release of $A C E$ into culture medium. The monolayer of monocytes obtained from peripheral blood was incubated in $4 \mathrm{ml}$ of F-10 medium without fetal bovine serum, and the medium was changed every day. The collected medium was centrifuged $20 \mathrm{~min}$ at $3,000 \mathrm{rpm}$ to remove any suspended cells, and the supernatant was assayed for ACE activity.

Measurement of ACE activity. ACE activity was measured by adding angiotensin $I$ to the reaction mixture and measuring generated angiotensin II by radioimmunoassay. Bradykinin-potentiating peptide B (BPP), angiotensin I, angiotensin II, and bestatin were purchased from Protein Research Foundation, Osaka, Japan. Pepstatin A was kindly provided by Dr. T. Aoyagi, Institute of Microbial Chemistry, Tokyo, Japan. Captopril was purchased from Squibb \& Sons, New York. ${ }^{125} \mathrm{I}$-angiotensin I and ${ }^{125} \mathrm{I}$-angiotensin II were obtained from New England Nuclear Co., Boston, MA. Other reagents were analytical grade and were obtained from commercial sources.

For ACE assays, $100-\mu l$ samples were added to a mixture of 100 $\mu$ l Hepes buffer $(0.05 \mathrm{M}, \mathrm{pH} 7.4)$ containing $90 \mathrm{mM} \mathrm{NaCl} ; 100 \mu \mathrm{l}$ pepstatin, an inhibitor of renin (17; final concentration, $1 \mathrm{mM}) ; 100$ $\mu l$ bestatin, an inhibitor of angiotensinase $(18,19$; final concentration, $0.1 \mathrm{mM}$ ); and $100 \mu \mathrm{l}$ angiotensin I substrate (final concentration, 12 $\mathrm{ng} / \mathrm{ml}$ ). The reaction was stopped by adding a solution containing 1 $\mu \mathrm{M}$ BPP and $1 \mathrm{mM}$ EDTA and cooling in an ice bath. Assays were carried out for $20 \mathrm{~min}$ at $37^{\circ} \mathrm{C}$ since the reaction was found to be linear for up to at least $30 \mathrm{~min}$.

The generated angiotensin II was measured by direct radioimmunoassay performed according to methodology described previously (20). Briefly, $700 \mu \mathrm{l}$ of $0.1 \mathrm{M}$ Tris buffer (pH 7.4) containing $30 \mathrm{mM}$ EDTA and $0.025 \%$ bovine serum albumin, and $0.005 \mu \mathrm{Ci}$ angiotensin II $(\sim 10,000 \mathrm{cpm})$ were mixed with $100 \mu \mathrm{l}$ angiotensin II antiserum $(1: 100,000$ titer). Sample $(100 \mu l)$ was added and the reaction mixture was incubated for $16-20 \mathrm{~h}$ at $4^{\circ} \mathrm{C}$. The antibody-bound and free angiotensin II were separated by addition of a dextran-coated charcoal suspension. Bound radioactivity was counted with a gamma scintillation counter. Without addition of the test sample, $75 \%$ of ${ }^{125}$ I-angiotensin II was bound to antiserum at final titer of $1: 100,000$. There was $0.5 \%$ cross-reactivity to angiotensin I and no cross reactivity to bestatin, pepstatin, or BPP. The sensitivity of the assay had a lower limit of 6 $\mathrm{pg} / \mathrm{ml}$. The SD of replicates from 10 standard curves was $0.28 \%$, and the coefficient of variation of 20 samples assayed in triplicate was $11.5 \%$.

Serum ACE activity was determined spectrophotometrically by a modification of the method described by Cushman and Chung (21). 1 unit of ACE is defined as $1 \mathrm{nmol} / \mathrm{min}$ hippuric acid released from hippuryl-L-histidyl-L-leucine ( $5 \mathrm{mM}$ initial concentration) at $37^{\circ} \mathrm{C}$.

Rabbit anti-ACE antibody. Antiserum against human plasma ACE was prepared in rabbits as previously described (22). Monospecificity was established by Ouchterlony double diffusion and confirmed by enzyme-linked immunosorbent assay $(23,24)$. Cells and culture medium that contained ACE activity were incubated with a 1:16 dilution of antiserum and subsequently assayed for ACE activity. ACE activity in the culture medium was calculated by subtracting ACE activity of the added antiserum from the residual activity measured in the presence of the antiserum.

\section{Results}

ACE activity in monocytes. While little or no ACE activity was detected in monocytes of normal volunteers under our assay conditions, monocytes from patients with sarcoidosis

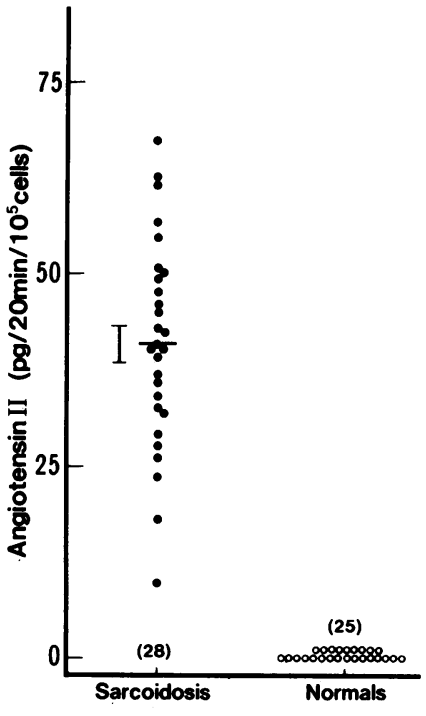

Figure 1. ACE activity in peripheral blood monocytes from patients with sarcoidosis. Monocytes were isolated and maintained in culture for $24 \mathrm{~h}$ before assay. The horizontal line indicates the mean and the bracketed line, the SEM.

generated angiotensin II ranging from 10 to $70 \mathrm{pg} / 20 \mathrm{~min}$ per $10^{5}$ cells (Fig. 1). This ACE activity remained constant for cells cultured for up to $6 \mathrm{~d}$. The ACE activity of monocytes from patients with sarcoidosis was inhibited by $95 \%$ when the cells were treated with $1 \mu \mathrm{g} / \mathrm{ml}$ cycloheximide for $72 \mathrm{~h}$ in culture before assay.

Release of $A C E$ into medium by monocytes. Considerably larger amounts of ACE than that contained in cells were released into serum-free culture medium by monocytes from patients with sarcoidosis (Fig. 2). When the cells were maintained in serum-free F-10 medium, ACE activity appeared in the medium in amounts from 10 to 20 times the amount found associated with the cells. Daily release of the enzymatic activity was nearly constant during $6 \mathrm{~d}$ of culture, and the number of cells in the dishes was not significantly changed during this period of incubation. More than $92 \%$ of the cells were viable even at the end of the culture period. ACE activity was not demonstrated in culture medium from monocytes obtained from normal volunteers (Fig. 2).

Characterization of the enzymatic activity. The enzymatic activity released by monocytes into the culture medium closely resembled classical ACE in several respects. It was inhibited

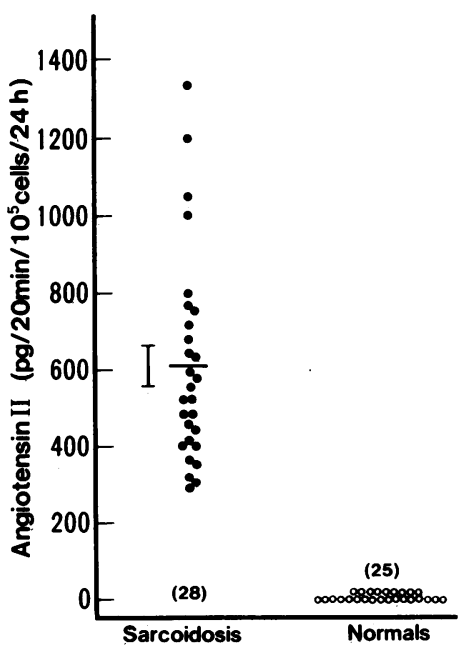

Figure 2. Release of ACE from sarcoidosis monocytes. Peripheral blood monocytes were cultured in $4 \mathrm{ml}$ of F-10 synthetic medium without serum. The medium was changed every day and the enzymatic activity in the medium was measured. ACE released during the first $24 \mathrm{~h}$ in culture is recorded. The mean $\pm \mathrm{SEM}$ is indicated. 
$97 \%$ by EDTA $(1 \mathrm{mM})$ and $95 \%$ by captopril $(10 \mu \mathrm{M})$. It was activated by chloride with a half maximal effect at $25 \mathrm{mM}$. Monocyte ACE was inhibited $66 \%$ by a 1:16 dilution of rabbit antiserum prepared against purified human plasma ACE. Such residual ACE catalytic activity is commonly observed after treatment of either crude ACE-containing samples or pure ACE with anti-ACE sera (16).

\section{Discussion}

Much interest has been focused in recent years on the cell populations of specific organs affected by sarcoidosis. There appears to be a preferential localization of activated $T$ helper lymphocytes in lungs of patients with this disease, while $T$ cells in the peripheral blood are reduced in number (25-28). In addition, monocytes in peripheral blood are activated and show increased IgG and C3 membrane receptors (29). Our study demonstrates that monocytes of the peripheral blood produce and release increased amounts of ACE in patients with sarcoidosis and that the ACE maintains characteristics of the enzyme found in plasma (22) and lung $(24,30)$.

The observation of increased ACE activity of monocytes of patients with sarcoidosis raises the question of whether these cells are committed to enhanced enzyme synthesis while still undergoing differentiation or are stimulated to produce and secrete increased amounts of enzyme after they arrive in the peripheral circulation. Helper $T$ cells from lungs of patients with sarcoidosis secrete a factor that is chemotactic for monocytes (26). Friedland et al. (31) observed that the very low base-line ACE activity in freshly isolated human peripheral blood monocytes was markedly elevated after $7 \mathrm{~d}$ when either T lymphocytes or lymphocyte/monocyte-conditioned medium was added to the monocyte culture containing $10 \%$ heatinactivated autologous serum. Induction of $\mathrm{ACE}$ was not stimulated by $T$ lymphocytes when filtered, heat-inactivated, pooled $\mathrm{AB}$ serum was substituted for autologous serum. Additional data presented by Rohrbach and Rolstad (32) showed the virtual absence of ACE activity in freshly isolated monocytes, an induction of ACE activity after $6 \mathrm{~d}$ of culture, and enhancement of ACE induction by both autologous serum and autologous $\mathrm{T}$ lymphocytes. In contrast, Silverstein et al. (33) reported that peripheral lymphocytes failed to induce ACE activity in monocytes from patients with sarcoidosis. Furthermore, these monocytes did not differ in ACE activity from those isolated from normal control subjects. When freshly isolated, they contained very low levels of ACE which rose upon culturing the cells for $7 \mathrm{~d}$ in heat-inactivated autologous serum, similar to the findings with normal macrophages (34). We have not found lymphocyte-derived factors to stimulate ACE of mouse peritoneal macrophages or those obtained from liver granulomas produced by schistosoma infection within $3 \mathrm{~d}$ of culture (35).

Our data does not corroborate that reported by Silverstein et al. (33) with respect to ACE activity in monocytes from patients with sarcoidosis. Perhaps our more sensitive assay offers the most obvious explanation for the discrepancy. Also, the culture medium may be critical to the observed difference. We cultured monocytes in synthetic serum-free medium (Hams F-10) whereas other investigators used different media (medium 199 and RPMI-1640) both with and without serum. The present studies provide support for a concept that monocytes of peripheral blood may be the source of elevated serum ACE in patients with sarcoidosis. That the enzyme measured in these studies is a true ACE was established by several criteria, including conversion of angiotensin I to angiotensin II, chloride dependency, and inhibition by EDTA, captopril (a specific ACE inhibitor), and monospecific antiserum to human ACE.

We must rationalize the discrepancy between our observation that all of our patients showed elevation of ACE in monocytes and the fact that only a portion of patients with sarcoidosis have elevated ACE in serum. Little is known about the turnover of ACE in serum even in normal subjects. The level of this enzyme in serum is remarkably stable and is replenished within 5-7 d after the level is lowered by plasmaphoresis (36). Serum ACE seems to be under some hormonal regulation since it is elevated in thyrotoxicosis (37). It is also elevated in serum of patients treated with the enzyme inhibitor captopril, suggesting that ACE is under feedback regulation by a reaction product such as angiotensin II $(38,39)$. The major normal base-line source of ACE in serum may be the endothelial cell since the endothelium is known to contain large amounts of ACE (40) and to release this enzyme when in culture (41). It is not known if the elevated ACE in serum of patients with sarcoidosis is an isoenzyme. Thus, even if elevation of serum ACE in sarcoidosis is derived from activated monocytes, the final level in serum may be determined by multiple factors affecting its production and turnover.

ACE activity is elevated in serum in a variety of diseases, and attention has been focused on its elevation in serum in sarcoidosis where there has been considerable variation in its sensitivity as a measurement for diagnosis and determination of activity of disease (5). It has been suggested that immunofluorescent analysis of lymph nodes from patients with sarcoidosis is a more sensitive index than the measurement of serum ACE activity for the diagnosis of sarcoidosis (8), but this determination requires a surgical procedure. Hence, the measurement of ACE activity in peripheral blood monocytes, as reported here, offers promise as a diagnostic procedure with a high degree of sensitivity. Also, further studies with peripheral blood monocytes of patients with sarcoidosis may better define "activity" of the disease and enhance our knowledge of the pathogenesis of sarcoidosis.

\section{References}

1. James, D. G. 1976. Sarcoidosis. In Textbook of Medicine. P. B. Beeson and W. McDermott, editors. W. B. Saunders Co., Philadelphia, PA. $165-175$.

2. Lieberman, J. 1975. Elevation of serum angiotensin converting enzyme (ACE) level in sarcoidosis. Am. J. Med. 59:365-372.

3. Fanburg, B. L., M. D. Schoenberger, B. Bachus, and G. L. Snider. 1976. Elevated serum angiotensin I converting enzyme in sarcoidosis. Am. Rev. Respir. Dis. 224:525-528.

4. Silverstein, E., J. Friedland, H. A. Lyons, and A. Gourin. 1976. Elevation of angiotensin converting enzyme in granulomatous lymph nodes and serum in sarcoidosis: clinical and possible pathogenic significance. Ann. NY Acad. Sci. 278:498-513.

5. Fanburg, B. L. 1983. Serum angiotensin-1-converting enzyme in the diagnosis and determination of activity in sarcoidosis. In Sarcoidosis and Other Granulomatous Diseases of the Lung. B. L. Fanburg, editor. Marcel Dekker, Inc., New York. 263-272.

6. Silverstein, E., J. Friedland, H. A. Lyons, and A. Gourin. 1976. Markedly elevated angiotensin-converting enzyme in lymph nodes containing non-necrotizing granulomas in sarcoidosis. Proc. Natl. Acad. Sci. USA. 73:2137-2141. 
7. Silverstein, E., J. Friedland, and T. Ackerman. 1977. Elevation of granulomatous lymph node and serum lysozyme in sarcoidosis and correlation with angiotensin-converting enzyme. Am. J. Clin. Pathol. 68:219-224.

8. Silverstein, E., L. P. Pertshuk, and J. Friedland. 1979. Immunofluorescent localization of angiotensin converting enzyme in epithelioid and giant cells of sarcoidosis granulomas. Proc. Natl. Acad. Sci. USA. 76:6646-6648.

9. James, E. M. V., and W. J. Williams. 1974. Fine structure and histochemistry of epithelioid cells in sarcoidosis. Thorax. 29:115-120.

10. Okabe, T., A. Suzuki, H. Ishikawa, H. Yotsumoto, and N. Ohsawa. 1981. Cells originating from sarcoid granulomas in vitro. Am. Rev. Respir. Dis. 124:608-612.

11. Hinman, L. M., C. Stevens, R. A. Matthey, and J. B. L. Gee. 1979. Angiotensin convertase activities in human alveolar macrophages: effects of cigarette smoking and sarcoidosis. Science (Wash. DC). 205: 202-203.

12. Thomas, E. D., R. E. Ramberg, G. E. Sale, R. S. Sparkes, and D. W. Golde. 1976. Direct evidence for a bone marrow origin of the alveolar macrophage in man. Science (Wash. DC). 192:1016-1018.

13. Böyum, A. 1968. Isolation of mononuclear cells and granulocytes from blood. II. Isolation of mononuclear cells by one centrifugation, and of granulocytes by combining centrifugation and sedimentation at $1 \times$ g. Scand. J. Clin. Lab. Invest. 21(Suppl. 97):77-89.

14. Nathan, C. F., R. Asofsky, and W. D. Terry. 1977. Characterization of the nonphagocytic adherent cell from the peritoneal cavity of normal and BCG-treated mice. J. Immunol. 118:1612-1621.

15. Li, C. Y., K. W. Lam, and L. T. Yam. 1973. Esterases in human leukocytes. J. Histochem. Cytochem. 21:1-12.

16. Das, M., and R. L. Soffer. 1976. Pulmonary angiotensinconverting enzyme antienzyme antibody. Biochemistry. 15:5088-5094.

17. Aoyagi, T., H. Morishita, R. Nisshizawa, S. Kunimoto, T. Takeuchi, and H. Umezawa. 1972. Biological activity of pepstatins, pepstanone $A$ and partial peptide on pepsin, cathepsin, and renin. $J$. Antibiot. (Tokyo). 25:689-694.

18. Umezawa, H., T. Aoyagi, H. Suda, M. Hamada, and T. Takeuchi. 1976. Bestatin, an inhibitor of aminopeptidase B, produced by actinomyces. J. Antibiot. (Tokyo). 29:97-101.

19. Nishizawa, R., T. Saito, T. Takita, H. Suda, T. Aotagi, and H. Umezawa. 1977. Synthesis and structure-activity relationships of bestatin analogues, inhibitors of aminopeptidase B. J. Med. Chem. 20:510515.

20. Yamagata, K., S. Murayama, and T. Ishido. 1981. Improved assay method for inactive and active forms of human renin. Rinshokensa. 25:919-922.

21. Cushman, D. W., and H. S. Chung. 1971. Spectrophotometric assay and properties of the angiotensin converting enzyme of rabbit lung. Biochem. Pharmacol. 20:1637-1648.

22. Lanzillo, J. J., and B. L. Fanburg. 1977. Angiotensin I converting enzyme from human plasma. Biochemistry. 16:5491-5494.

23. Weinberg, K. H., W. H. J. Douglas, D. R. MacNamee, J. J. Lanzillo, and B. L. Fanburg. 1982. Angiotensin-I-converting enzyme localization on cultured fibroblasts by immunofluorescence. In Vitro. 18:400-406.

24. Lanzillo, J. J., and B. L. Fanburg. 1982. Development of competitive enzyme immunoassays for human serum angiotensin-1converting enzyme: a comparison of four assay configurations. Anal. Biochem. 126:156-164.

25. Hunninghake, G. W., J. D. Fulmer, R. C. Young, J. E. Gadek, and R. G. Crystal. 1979. Localization of the immune response in sarcoidosis. Am. Rev. Respir. Dis. 120:49-57.

26. Hunninghake, G. W., J. E. Gadek, R. C. Young, O. Kawanami, V. J. Ferrans, and R. Crystal. 1980. Maintenance of granuloma formation in pulmonary sarcoidosis by $\mathrm{T}$ lymphocytes within the lung. N. Engl. J. Med. 302:594-598.

27. Daniele, R. P., and D. T. Rowlands, Jr. 1976. Lymphocyte subpopulation in sarcoidosis: correlation with disease activity and duration. Ann. Intern. Med. 85:593-600.

28. Daniele, R. P., J. H. Dauber, and M. D. Rossman. 1980 Immunologic abnormalities in sarcoidosis. Ann. Intern. Med. 92:406416.

29. Douglus, S. D., C. D. Daughaday, M. E. Schmidt, and L. E. Silzbach. 1976. Kinetics of monocyte receptor activity for immunoproteins in patients with sarcoidosis. Ann. NY Acad. Sci. 278:190-200.

30. Nishimura, K., N. Yoshida, K. Hiwada, E. Ueda, and T. Kokubu. 1978. Properties of three different forms of angiotensin-1converting enzyme from human lung. Biochim. Biophys. Acta. 522: 229-237.

31. Friedland, J. E., E. Silverstein, C. Setton, T. Ackerman, and M. Drooker. 1979. Angiotensin converting enzyme induction in human monocytes in culture stimulated by T-lymphocytes and by a soluble factor present in lymphocyte-monocyte conditioned media. Clin. Res. 27:397. (Abstr.)

32. Rohrbach, M. S., and R. A. Rolstad. 1983. Comparison of the induction of angiotensin converting enzyme and leucine aminopeptide in cultured human monocytes. Fed. Proc. 42:2130. (Abstr.)

33. Silverstein, E., J. Friedland, T. Ackerman, and C. Setton. 1979. Angiotensin converting enzyme induction in human monocytes in culture. Lack of stimulation of autologous peripheral lymphocytes in sarcoidosis. Clin. Res. 27:404. (Abstr.)

34. Friedland, J., C. Setton, and E. Silverstein. 1978. Induction of angiotensin converting enzyme in human monocytes in culture. Biochem. Biophys. Res. Commun. 83:843-849.

35. Krulewitz, A. W., M. J. Stadecker, J. A. Wright, and B. L. Fanburg. 1983. Angiotensin-1-converting enzyme activity of murine macrophages isolated from granulomas elicited by eggs of Schistosoma mansoni. Infect. Immun. 41:39-43.

36. Silberstein, L. E., E. M. Berkman, and B. L. Fanburg. 1983. Angiotensin-1-converting enzyme (ACE) activity in serum following plasma exchange. Proc. Soc. Exp. Biol. Med. 173:222-226.

37. Yotsumoto, H., Y. Imai, N. Kaznya, H. Uchimura, and F. Matsuzaki. 1982. Increased levels of serum angiotensin-converting enzyme activity in hyperthyroidism. Ann. Intern. Med. 96:326-328.

38. Larochelle, P., J. Genest, O. Kuchel, R. Boucher, Y. Gutkowska, and D. McKinstry. 1979. Effect of captopril (SQ 14225) on blood pressure, plasma renin activity and angiotensin-1-converting enzyme activity. Can. Med. Assoc. J. 121:309-316.

39. Boomsma, F., J. H. B. de Bruyn, F. H. M. Derkx, and M. A. D. H. Schalekamp. 1981. Opposite effects of captopril on angiotensin-1-converting enzyme activity and concentration: relation between enzyme inhibition and long-term blood pressure response. Clin. Sci. 60:491-498.

40. Ryan, J. W., U. Smith, and R. S. Neimeyer. 1972. Angiotensin I: metabolism by plasma membrane of lung. Science (Wash. DC). 176: 64-66.

41. Krulewitz, A. H., and B. L. Fanburg. 1981. The effect of oxygen tension on the in vitro production and release of angiotensinconverting enzyme by bovine pulmonary artery endothelial cells. $\mathrm{Am}$. Rev. Respir. Dis. 130:866-869. 